\title{
La mediación civil en España: luces y sombras de un marco normativo
}

\author{
Leticia GARCÍA VILLALUENGA \\ Universidad Complutense de Madrid \\ l.g.villalulenga@trs.ucm.es \\ Eduardo VÁZQUEZ DE CASTRO \\ Universidad de Cantabria \\ eduardo.vazquez@unican.es
}

Recibido: 04/06/2012

Aceptado: 13/11/2012

\begin{abstract}
Resumen
En España se ha traspuesto recientemente la Directiva 52/2008 sobre mediación en asuntos civiles y mercantiles a través de la Ley 5/2012, de 6 de julio, de Mediación en Asuntos Civiles y Mercantiles. El texto normativo aprobado se ha construído en buena parte sobre la base del malogrado Proyecto de la Legislatura anterior. De otro lado, en los distintos territorios autonómicos se han llevado a cabo numerosas y diversas iniciativas legislativas en el ámbito de la mediación que muestran la fuerte expansión de esta institución. Por último, observando la coyuntura de la práctica actual, se aprecia la paulatina consolidación de la mediación entre los operadores jurídicos, quedando reflejada en resoluciones de jueces y tribunales. Todos estos elementos invitan a la reflexión sobre el modelo adoptado en nuestra flamante normativa de mediación en asuntos civiles y mercantiles.
\end{abstract}

Palabras clave mediación, conflictos familiares, Ley 5/2012, Directiva 52/2008, separación y divorcio, asuntos civiles y mercantiles.

\section{The civil mediation in Spain: lights and shades of a normative frame}

\begin{abstract}
Directive 52/2008 on mediation in civil and commercial matters has been recently transposed in Spain by the Law 5/2012, of July 6, of Mediation in Civil and Mercantile Matters. The normative text is mostly based on the unsuccessful Project of the previous Legislature. On the other hand, in different autonomous territories have implemented numerous and various legislative initiatives in the field of mediation that show the strong expansion of this institution. Finally, noting the situation of current practice, we see the gradual consolidation of mediation between legal operators, being reflected in decisions of judges and courts. All these elements invite reflection on the model adopted in our brand new rules of mediation in civil and commercial matters

Keywords: mediation, familiar matters, Law 5/2012, Directive 52/2008, separation and divorce, civil and commercial matters.

\section{Referencia normalizada}

García Villaluenga, L., Vázquez de Castro, E. (2013). "La mediación civil en España: luces y sombras de un marco normativo”. Política y Sociedad, Vol.50 núm. 1: páginas.71-98
\end{abstract}


Sumario: 1.Consideraciones generales. El interés de la Unión Europea por la mediación y su recepción en España. 2.La mediación y su regulación en España en el ámbito familiar como desarrollo natural de un nuevo régimen jurídico. 3.Coyuntura de la práctica de la mediación en España. 4.La mediación en la jurisprudencia. Receptividad judicial y evolución de los principios. 5.El resultado de la evolución: la Ley española de mediación en asuntos civiles y mercantiles. 6.La Oportunidad de la Ley estatal de mediación en asuntos civiles y mercantiles. 7.Referencias bibliográficas

\section{Consideraciones generales. El interés de la Unión Europea por la media- ción y su recepción en España.}

La observación actual de las relaciones sociales permite advertir, en primer lugar, su creciente conflictividad y, en segundo, la necesidad de mostrar a los ciudadanos la importancia de atender a la solución de los mismos, antes que fomentar su constante recurso a los órganos jurisdiccionales. En este sentido se expresa el Libro verde de la UE (COM 2002/196) sobre modalidades alternativas de solución de conflictos en el ámbito del derecho civil, y a este fin se orienta el desarrollo de la mediación.

La mediación es una materia emergente, actual y de honda trascendencia social y jurídica, y su desarrollo, al igual que el del resto de las denominadas ADR (Alternative Dispute Resolution), responde a la necesidad de mejorar el acceso a la justicia como apuesta política de la Unión Europea. Al mismo tiempo, la mediación se perfila como instrumento de paz social que conlleva una mayor participación cívica, respondiendo, así, a un concepto amplio de hacer justicia desde y para sus protagonistas

Estos criterios han estado presentes en distintos instrumentos internacionales de la Unión Europea, como han sido las Recomendaciones R (86) 12 del Consejo de Ministros de los estados miembros, respecto a medidas para prevenir y reducir la carga de trabajo excesiva en los Tribunales y la R (98) 1 del Consejo de Ministros a los estados miembros, sobre la Mediación Familiar, así como en la trascendente Directiva Europea 2008/52/CE, sobre Mediación en Asuntos Civiles y Mercantiles (Diario Oficial de la Unión Europea C 198/1, 12.8.2005) ${ }^{1}$.

${ }^{1}$ El interés de la Unión Europea en el desarrollo y aplicación de la mediación quedaba ya patente en el contenido del "Plan de Acción del Consejo y la Comisión por el que se aplica el Programa de la Haya sobre refuerzo de la libertad, la seguridad y la justicia en la Unión Europea” (Diario Oficial de la Unión Europea C 198/1, 12.8.2005). Dentro de la búsqueda de este Espacio Europeo de la Seguridad y la Justicia encuentran cabida los sistemas de resolución extrajudicial de conflictos. En concreto, interesa especialmente el punto h), que recoge la necesidad de "adopción de la Directiva sobre ciertos aspectos de la mediación en asuntos civiles y mercantiles” para 2006, fecha en la que la primitiva Propuesta de Directiva sobre mediación debiera haber estado aprobada. 
La referida Directiva, que sienta las bases para garantizar en la Unión Europea un marco jurídico "predecible” para quienes quieran recurrir a la mediación, promoviendo así un mayor uso de la misma ${ }^{2}$, nace con la limitada vocación de aplicación a conflictos transfronterizos ${ }^{3}$. Sin embargo, abre la posibilidad a que los estados miembros apliquen las mismas reglas en los procedimientos de mediación de carácter nacional, lo que ha determinado que se haya tomado como modelo para la legislación interna de muchos países de la UE.

El impacto de la Directiva citada en la institución de la mediación y en la aceptación de ésta por los Tribunales de los Estados de la Unión, es enorme. Buena prueba de ello es el Informe de la Comisión de Asuntos Jurídicos sobre la aplicación de dicha Directiva en los estados miembros, que finaliza con una Propuesta de Resolución por el Parlamento Europeo en la que se apuesta decididamente por incluir la mediación como uno de los accesos a la Administración de justicia 4 .

La mediación, como sistema cooperativo de gestión, transformación y solución de conflictos favorece la comunicación entre las partes para que tomen sus propias decisiones, por ello, es notable el compromiso de quienes participan en el proceso de mediación, lo que conlleva también un alto índice de cumplimiento de los acuerdos. Es por ello que se ha mostrado idóneo para ser aplicado en diferentes ámbitos (SOLETO MUÑOZ, 2011) ${ }^{5}$, habiendo tenido un amplio desarrollo en los conflictos familiares.

La mediación en España tiene un importante grado de aplicación, pudiendo afirmarse que su implementación ha ido por delante de la norma jurídica (GARCÍA VILLALUENGA, 2006: 315 y ss.) ${ }^{6}$. Así, en el ámbito estatal, fue definitiva la aparición de la mediación en la Ley 15/2005, de 8 de julio, por la que se modificaron el Código Civil y la Ley de Enjuiciamiento Civil en materia de separación y divorcio. La inclusión de la mediación en el artículo $770.7^{\circ}$ de la Ley de Enjuiciamiento Civil, como posibilidad de que las partes suspendan el proceso para acoger-

\footnotetext{
${ }^{2}$ Vid. Considerando $7^{\circ}$ de la Directiva 2008/52, del Parlamento Europeo y del Consejo, sobre ciertos aspectos de la mediación en asuntos civiles y mercantiles de 21 de mayo de 2008.

${ }^{3}$ La malograda Propuesta de Directiva Proyecto de Directiva de 2004 fue más ambiciosa en este sentido. COM(2004) 718 final, 2004/0251 (COD), Propuesta de Directiva del Parlamento Europeo y del Consejo sobre ciertos aspectos de la mediación en asuntos civiles y mercantiles \{SEC(2004) 1314\}, presentada por la Comisión el 22 de octubre de 2004.

${ }^{4}$ Documento de sesión del Parlamento Europeo 2009 - 2014, A7-0275/2011, 15.7.2011. INFORME de la Comisión de Asuntos Jurídicos sobre la aplicación de la Directiva sobre la mediación en los Estados miembros, su impacto en la mediación y su aceptación por los Tribunales (2011/2026(INI)) y Propuesta de Resolución adoptado por unanimidad.

${ }^{5}$ SOLETO MUÑOZ, H. (2011): Mediación y resolución de conflictos: técnicas y ámbitos. Ed. Tecnos, Madrid.

${ }^{6}$ GARCÍA VILLALUENGA, L. (2006): Mediación en conflictos familiares. Una construcción desde el derecho de familia. Ed. Reus, Madrid.: 315 y ss.
} 
se a la misma, supuso una apuesta legal por potenciar estas vías de solución. Asimismo, la disposición final tercera de la Ley 15/2005, instó al Gobierno a remitir a las Cortes un Proyecto de Ley sobre Mediación basado en los principios establecidos en las disposiciones de la Unión Europea, y, en todo caso, en los de voluntariedad, imparcialidad, neutralidad y confidencialidad y en el respeto a los servicios de mediación creados por las Comunidades Autónomas. Este hecho, junto a la necesidad de trasponer la Directiva 2008/52/CE, a tenor de su artículo $12^{7}$, trajo como consecuencia la gestación del Proyecto de Ley estatal de Mediación en Asuntos Civiles y Mercantiles, de 8 de abril de $2011^{8}$, que no vio finalizada su tramitación en la legislatura al disolverse las Cortes y anticiparse las elecciones generales ${ }^{9}$.

Ciertamente, la Unión Europea ya había advertido a los Estados de la posible infracción ante el incumplimiento del plazo marcado para la transposición de la Directiva, que venció el 21 de mayo de 2011. Así, en julio de 2011 la Comisión envió "cartas de emplazamiento" (letters or formal notice) a nueve países: República Checa, España, Francia, Chipre, Luxemburgo, los Países Bajos, Finlandia, Eslovaquia y Reino Unido, tres de los cuales (Finlandia, Eslovaquia y Reino Unido) comunicaron a la Comisión sus medidas nacionales para la transposición de la Directiva.

En esta coyuntura se ha materializado la incorporación de la Directiva a España, mediante la aprobación del Real Decreto-Ley 5/2012, de 5 de marzo, de Mediación en Asuntos Civiles y Mercantiles ${ }^{10}$, convalidado por el Congreso de los Diputados

${ }^{7}$ Artículo 12. Incorporación al ordenamiento jurídico de los estados miembros: “1. Los estados miembros pondrán en vigor las disposiciones legales, reglamentarias y administrativas necesarias para dar cumplimiento a la presente Directiva antes del 21 de mayo de 2011, con excepción del artículo 10, al que deberá darse cumplimiento el 21 de noviembre de 2010 a más tardar...”.

${ }^{8} \mathrm{Al}$ dicho Proyecto le precedió el Anteproyecto de Ley de Mediación en Asuntos Civiles y Mercantiles, de 19 de febrero de 2010.

${ }^{9}$ Proyecto de Ley 121/000122, de mediación en asuntos civiles y mercantiles, publicado en el BOCG de 29 de abril de 2011, Núm. 122-1.

${ }^{10}$ La utilización de la vía del Real Decreto Ley, prevista en el art. 86 de la Constitución Española, en base a la "extraordinaria y urgente necesidad", ha sido cuestionada por algunos sectores que entienden que se ha "sustraído" al amplio debate de ambas Cámaras un tema de gran trascendencia y de hondo compromiso institucional y social como es éste.

En efecto, en cumplimiento de lo dispuesto en el artículo 86.2 de la Constitución, el Real Decreto-ley 5/2012, de 5 de marzo, de mediación en asuntos civiles y mercantiles (núm. expte. 130/000006), fue sometido a debate y votación de totalidad por el Congreso de los Diputados en su sesión del día 29 de marzo de 2012, en la que se acordó su convalidación, según texto publicado en el BOE núm. 56, de 6 de marzo de 2012, y corrección de errores publicada en el BOE núm. 65, de 16 de marzo de 2012. Asimismo, se dispuso su tramitación como Proyecto de Ley (núm. expte. 121/000005). Consecuencia de ello, la Mesa del Congreso de los Diputados acordó su remisión a la Comisión de Justicia para su aprobación, con competencia legislativa plena, así como abrir el plazo para presentar enmiendas por Dipu- 
el 29 de marzo de 2012 y tramitado posteriormente como Proyecto de Ley por vía de urgencia, concluyendo con la Ley 5/2012, de 6 de julio, de Mediación en Asuntos Civiles y Mercantiles. El texto normativo aprobado se ha construido en buena parte sobre la base del malogrado Proyecto de la Legislatura anterior con cambios puntuales en su articulado que tienden a simplificar la norma.

La Ley estatal de Mediación en Asuntos Civiles y Mercantiles deja fuera de su ámbito de aplicación la mediación penal, con las Administraciones Públicas, la laboral y en consumo (art. 2.2). Ciertamente, se excluyen las materias que no afectan al ámbito civil y mercantil, salvo en lo referente al consumo ${ }^{11}$.

La inactividad o la infructífera actividad del legislador estatal no se corresponde con la progresiva actividad que ha venido desarrollando el legislador autonómico. Así, se puede afirmar que, en la mayoría de territorios con autonomía legislativa, se han preocupado de regular la mediación. En algunos casos, incluso, existen autonomías en las que ya hay una segunda Ley de Mediación más moderna que viene a sustituir a la anterior. Ciertamente, en el ámbito autonómico han sido 13 las Comunidades Autónomas que han visto la oportunidad de legislar y regular la institución de la mediación, haciéndose eco de su creciente importancia y conveniencia ${ }^{12}$.

tados y Grupos Parlamentarios. Dicho Proyecto de Ley se ha tramitado por el procedimiento de urgencia, de conformidad con el último inciso del apartado 4 del artículo 151 del Reglamento de la Cámara, y en el momento de cerrar este artículo se han ampliado las prórrogas a la presentación de enmiendas.

${ }^{11}$ En realidad, no se incluye la mediación en materia de consumo, al igual que ocurría en la Directiva transpuesta, puesto que dicha mediación implica unas especificidades que requieren una regulación especial. Téngase en cuenta que la Recomendación 98/257/CE, de 30 de marzo de 1998, relativa a los principios aplicables a los órganos responsables de la solución extrajudicial de los litigios en materia de consumo fue el primer impulso que la Unión Europea aportó a los sistemas extrajudiciales de resolución de conflictos de consumo (http://eur-lex.europa.eu/LexUriServ/LexUriServ.do?uri=CELEX:31998H0257:ES:NOT).

La Comisión elabora una nueva Recomendación de 4 de abril de 2001, relativa a los principios aplicables a los órganos extrajudiciales de resolución consensual de litigios en materia de consumo, siendo incluida, esta vez, la mediación.

http://ec.europa.eu/consumers/redress/out_of_court/adr/acce_just12_es.pdf

${ }^{12}$ Así, pueden citarse: la Ley 1/2011, de 28 de marzo, de Mediación de la CA de Cantabria, la Ley 9/2011, de 24 de marzo, de mediación familiar de Aragón, Ley 14/2010, de 9 de diciembre, de mediación familiar de las Islas Baleares (que deroga la Ley 18/2006, de 22 de noviembre, de mediación familiar);la Ley de Cataluña 15/2009, de 22 de julio, de mediación en el ámbito del derecho privado (que ha derogado la Ley 1/2001, de 15 de marzo, de mediación familiar de Cataluña), la Ley 1/2009, de 27 de febrero, reguladora de la Mediación Familiar en la CA de Andalucía, la Ley 1/2007, de 21 de febrero, de Mediación en la Comunidad de Madrid, la Ley 3/2007, de 23 de marzo, de Mediación Familiar del Principado de Asturias, la Ley 1/2008, de 8 de febrero, de Mediación Familiar del País Vasco, la Ley 1/2006, de 6 de abril, de Mediación Familiar de Castilla y León, la de Castilla La Mancha, Ley 4/2005, de mayo, del Servicio Social Especializado de Mediación Familiar, Canarias 
Toda esta normativa autonómica específica, que en ocasiones se formula desde diversas premisas, con mayor o menor competencia ${ }^{13}$, presenta, en todo caso, una preocupación común: contribuir a la solución y prevención de los conflictos, fomentando la disposición a ello de los propios sujetos implicados.

Una de las tendencias claramente apreciables en la regulación de la mediación por las Comunidades Autónomas, debido en buena medida al efecto de la Directiva 2008/52, es la relativa a la expansión de la mediación a todos los ámbitos. Así, dos de las últimas leyes autonómicas escapan del ámbito familiar para ampliar su objeto a otros entornos conflictivos del derecho privado e incluso del derecho público. En esta nueva tendencia se encuentran la Ley 15/2009, de 22 de julio, de Cataluña de mediación en el ámbito del derecho privado y la Ley 1/2011, de 28 de marzo, de Mediación de la CA de Cantabria. Merece destacarse que esta última ley contempla la mediación con carácter integral, y por lo tanto, también, -pero no exclusivamente-, en los ámbitos civil y mercantil, comprendiendo, además, la mediación en el ámbito social, administrativo y penal.

No obstante, con independencia de la existencia de un marco legal, se ha venido observando un incremento exponencial del ejercicio de la actividad mediadora en todo el territorio del Estado. Asimismo, profesionales de formación diversa se han interesado por esta institución al objeto de introducir la mediación como herramienta útil y eficaz en la resolución extrajudicial de conflictos y poder descubrir toda su virtualidad práctica. Las Universidades españolas y algunos Colegios Profesionales se han ido adelantando a la regulación formal de la actividad ofreciendo formación y apoyo a quienes pretenden capacitarse y ofrecer servicios de mediación bajo los principios de la autonomía de la voluntad, el diálogo y el consenso. No obstante, resulta necesario uniformar criterios sobre la figura, profesionalidad y la labor del

con su Ley 15/2003, de 8 de abril, Ley de la mediación familiar de Canarias; la Ley 7/2001, de 26 de noviembre, Reguladora de la Mediación Familiar en el ámbito de la Comunidad Valenciana y la Ley 4/2001, de 31 de mayo, Reguladora de la Mediación Familiar en Galicia. En Navarra se está tramitando en el momento actual un Borrador de Decreto Foral que regula el Servicio de Mediación familiar. Este borrador da cumplimiento a la Ley Foral 3/2011, de 17 de marzo, sobre custodia de los hijos en caso de ruptura de la convivencia de los padres y el Gobierno de Navarra ha considerado conveniente articular la audiencia y participación de la población navarra en el procedimiento de elaboración de esta norma mediante el trámite de información pública, a fin de que las alegaciones presentadas puedan ser debidamente valoradas e incorporadas al expediente.

${ }^{13}$ Las competencias de las Comunidades Autónomas para dictar Leyes de mediación familiar no se encuentran entre las que la Constitución reconoce para la conservación, modificación y desarrollo de los Derechos civiles, forales o especiales (ello hubiera impedido que algunas Comunidades que han dictado leyes lo hicieran al no tener las referidas competencias civiles. ex art. 149.1.8 CE), sino que, más bien, se basa en las relativas a asistencia social, contempladas en el art. 148.1.20 de la CE. 
mediador como un técnico bien preparado, un tercero neutral e imparcial en un conflicto ajeno, que desplegará toda su actividad y empeño en lograr el entendimiento entre las partes y reflejarlo en un acuerdo común en el que son los propios implicados los que encuentran y asumen la solución a sus problemas. No obstante, esta es también tarea pendiente en toda Europa que debe pensar en la calidad de los mediadores europeos, tal y como deja entrever la Directiva (VÁZQUEZ DE CASTRO, GARCÍA VILLALUENGA, 2010: 63-83) ${ }^{14}$.

En la práctica española, la figura de la mediación se presenta como una metodología que puede resultar clave para el entendimiento de las parejas que se enfrentan a una crisis matrimonial en el nuevo marco del Derecho de Familia, pero también para resolver otro tipo de conflictos familiares (herencias, alimentos, tutela, empresa familiar, adopción...) (GARCÍA VILLALUENGA, 2006:345 a 379) ${ }^{15}$, así como aquéllos que se presentan en ámbitos diversos al familiar (mediación en el ámbito penal, comunitario, escolar, sanitario, organizacional, etc).

La mediación se ha ido introduciendo tímidamente en España como sistema que asiste a las partes en las tareas de comprender su disputa, mejorar su comunicación, ayudar a transformarla y tratar de hallar un acuerdo que promueva la convivencia respetuosa y pacífica entre ellas. En estos momentos, el avance, expansión y reconocimiento de la mediación como actividad técnica y profesional es incuestionable, buena prueba de ello es la Ley 5/2012, de 6 de julio de Mediación en Asuntos Civiles y Mercantiles que ha venido a consagrar esta realidad, dando homogeneidad, ofreciendo seguridad jurídica y respaldando la institución mediadora institucionalmente.

\section{La mediación y su regulación en España en el ámbito familiar como desa- rrollo natural de un nuevo régimen jurídico.}

La regulación en España de la mediación no puede disociarse del ámbito familiar al que se ha tendido a circunscribir la legislación autonómica actualmente vigente. No puede concebirse, por consiguiente, la regulación de la mediación familiar en España fuera del marco de la propia regulación de la familia. El interés del legislador autonómico por regular la mediación en el ámbito familiar no es casual, sino que

${ }^{14}$ Sobre la profesionalidad del mediador, vid VÁZQUEZ DE CASTRO, E., GARCÍA VILLALUENGA, L. (2010) "La mediación y la formación del mediador. ¿dos caras de una misma moneda?”, Mediación, arbitraje y resolución extrajudicial de conflictos en el siglo XXI. La Mediación. ed. Reus, Tomo I. Madrid,: 63-83.

${ }^{15}$ Sobre los ámbitos de la mediación familiar, vid. GARCÍA VILLALUENGA, L.: La mediación en conflictos familiares: Una construcción desde el derecho de familia: 345 a 379. 
obedece a una evolución social y jurídica del régimen jurídico aplicable a la familia. Como es sabido, el modelo familiar en España ha evolucionado de modo notable en las últimas décadas y el ordenamiento jurídico español ha tratado de dar respuesta puntual a las nuevas realidades familiares. La igualdad efectiva entre los cónyuges, el matrimonio entre personas del mismo sexo y el nuevo régimen de separación y divorcio son aspectos que han influido en la natural aplicación de la metodología de la mediación ante conflictos o problemas que pueden resolverse de una manera diversa a la que tradicionalmente se concebía. Sin duda, la mediación va unida al proceso de cambio y facilita ese cambio o evolución normalizando y racionalizando las nuevas relaciones familiares.

Ciertamente, España ha experimentado un proceso de reforma legislativa en materia de derecho de familia que da buena muestra de la evolución misma de los propios modelos familiares que se están produciendo en la sociedad (DIEZ PICAZO y GULLÓN, 2006: 39) ${ }^{16}$. No existe ningún texto legal que defina la familia, aunque se regulen todo tipo de relaciones familiares y sea una referencia constante en numerosa normativa. El concepto jurídico de familia ha protagonizado inexorablemente una importante transformación; basta con repasar las definiciones que ofrecían y ofrecen algunos textos universitarios de referencia (CASTÁN TOBEÑAS, 1994:39 y LACRUZ BERDEJO, 2005:1) ${ }^{17}$. Lo más acertado es considerar que no se puede concebir un concepto intemporal de familia. Como afirman Díez-Picazo y Gullón, "más exacto que hablar de familia en singular, como institución universal y única, sería hablar de 'familias' en plural para designar modelos con arreglo a los cuales los grupos humanos se han organizado históricamente". Pudiendo añadirse que en el punto actual de evolución, que aún no ha acabado,

${ }^{16}$ DÍEZ-PICAZO y GULLÓN (2006) "Evolución profunda originada por los cambios producidos en los hábitos y en las creencias sociales” según Sistema de Derecho Civil, Vol. IV, Madrid,: 39.

${ }^{17}$ CASTÁN TOBEÑAS (1994), consideraba "en un sentido jurídico amplio, entendemos por familia el conjunto de personas unidas por el matrimonio o por los vínculos del parentesco (natural o de adopción)" y "en un sentido estricto, se llama actualmente familia al grupo restringido formado por los cónyuges y por los padres e hijos con exclusión de los demás parientes, o al menos de los colaterales" en Derecho Civil Común y Foral, T.V, Vol $1^{\circ}$, Madrid,: 39. En cambio, si observamos textos más recientes se comprueba el cambio LACRUZ BERDEJO y otros, (2005) al decir que "la familia aparece en la historia y en la actualidad como una comunidad que, creada en principio por el matrimonio, está compuesta, al menos, por progenitores y procreados, y en la que pueden participar otras personas, convivientes o no. Al lado de este tipo de familia tradicional, mayoritaria y todavía considerada socialmente como referencia existen relaciones familiares no fundadas en los vínculos propios del matrimonio" en Elementos de Derecho Civil , T. IV, Familia, 2 ${ }^{\mathrm{a}}$ ed., Madrid,: 1. 
también resulta más acertado hablar de modelos familiares en plural que de familia en singular ${ }^{18}$.

No procede en este estudio realizar un repaso de la evolución histórica de la familia, aunque conviene destacar que el Código Civil de 1889 supuso el mantenimiento de la fortísima tradición religiosa española que la identificaba con el matrimonio canónico. Esta situación existente en los inicios de nuestro Código Civil, se modificó efímeramente en la Segunda República, con la Constitución de 9 de diciembre de 1931. Dicha Constitución proclamaba un régimen aconfesional del matrimonio, reimplantándose el matrimonio civil obligatorio en el año 1932, e instaurándose el principio de igualdad de derechos para ambos sexos, la disolución del matrimonio mediante divorcio y los mismos deberes de los padres frente a los hijos nacidos dentro y fuera del matrimonio. Toda esta situación fue nuevamente modificada, tras la Guerra Civil, en el año 1938. La Ley de 12 de marzo de 1938 deroga la Ley de Matrimonio Civil de 1932, se vuelve al régimen estatal de confesionalidad para el matrimonio, se derogaron todas las normas del matrimonio civil, se restaura el régimen de indisolubilidad del matrimonio, y se restablece el matrimonio canónico y la distinción entre hijos legítimos e ilegítimos. Esta situación continúa hasta el año 1958, donde se reconocen las dos clases de matrimonio, obligándose a los católicos a contraer por la forma del matrimonio católico, autorizándose el matrimonio civil cuando se probara que ninguno de los contrayentes profesara la religión católica. Esta situación cambia tras la promulgación de la ley de libertad religiosa de 28 de junio de 1967, que relajó la necesidad de prueba de no profesar la religión católica, que se requería para poder contraer matrimonio civil, provocándose así el cambio de un sistema de "matrimonio civil subsidiario" (existente hasta ese momento) a un sistema matrimonial "electivo" (a voluntad de los contrayentes). La normativa civil familiar se dirige, pues, hacia la eliminación de las desigualdades entre los hijos matrimoniales o extramatrimoniales, y hacia la equiparación de los deberes y derechos de los cónyuges (así ocurrió con la Ley de 2 de mayo de 1975 por la que se eliminó el deber de obediencia de la esposa).

Finalmente, con la democracia y la Constitución española de 1978 se establece un marco constitucional del Derecho de Familia en el que encuentran cabida diversos modelos junto con el matrimonial. Ciertamente, aunque el matrimonio sigue siendo una forma privilegiada de acceso a la familia (artículo 32 de la Constitución Española (CE) ${ }^{19}$ convive con otras formas familiares que deben gozar de la misma

${ }^{18}$ Debe entenderse el artículo 39 de la constitución española cuando habla de protección jurídica y economía económica de la familia, está haciendo referencia a cualquier modelo de familia nuclear (pareja, pareja con hijos, progenitor conviviente con los hijos).

${ }^{19}$ El Tribunal Constitucional al referirse a los artículos 32 y 39 de la Constitución ha manifestado que la familia no se identifica con el matrimonio y existen otras modalidades que también se encuentran protegidas por la Constitución. No obstante, no se considera que el matrimonio y la convivencia extramatrimonial sean "realidades equivalentes". (SSTC 222/1992, de 11 de diciembre, 116/1999, de 17 de junio). Por este motivo, ante la laguna 
protección y respeto (artículos 39 CE). Incluso, la institución matrimonial ha experimentado un acusado cambio en su concepción jurídica al poder comprender también a personas del mismo sexo ${ }^{20}$.

Si importante ha sido la evolución del concepto de familia, no menos importante han resultado las reformas referentes a las crisis matrimoniales. Cuando la Ley del divorcio de 1981 contaba con casi veinticinco años de vigencia y aplicación, empieza a constatarse que los ya habituales procesos de separación y divorcio resultan convertirse en un arduo, costoso y lento recorrido que incrementa la tensión emocional de la crisis matrimonial, lejos de solucionarla.

Hay que ser conscientes de que en el año 1981 la promulgación de una ley reguladora del divorcio no estuvo exenta de gran polémica y contestación por parte de los grupos más conservadores. Finalmente, la ley que resultó aprobada posibilitaba el divorcio o la disolución del matrimonio, pero como último remedio. No se podía acceder al divorcio directamente sino que, mediando siempre una previa separación, debería alegarse alguna de las causas tasadas en el Código civil. Además, no podía iniciarse ningún trámite de separación judicial hasta que no hubiere transcurrido un año de duración del matrimonio. La consecuencia era un divorcio de muy difícil acceso y generador de grandes tensiones entre cónyuges. Resultaba paradójico la gran facilidad que existía para contraer matrimonio ${ }^{21}$, en contraste con la extraordinaria dificultad para divorciarse.

Estas deficiencias constatadas de los procesos de separación y divorcio provocan, además, inconvenientes añadidos a las ya problemáticas crisis matrimoniales que buscan en los tribunales alguna solución a sus conflictos. Los inconvenientes añadidos que acarreaba el proceso judicial venían determinados por las tensiones propias de las formalidades y rigores de un pleito, la dilatada duración del mismo, los costes económicos y la estandarización de soluciones judiciales para conflictos compuestos por intereses y necesidades muy diversas.

Para poner fin a estas deficiencias se promulga la Ley 15/2005, de 8 de julio, en cuyo articulado se ha venido a dar buena solución a algunas de las carencias detectadas en la regulación del Código Civil y Ley de Enjuiciamiento Civil en materia de

legal en el ámbito estatal las CC.AA. se han lanzado a regular y reglamentar la convivencia extramatrimonial, en algunos casos con buenas intenciones y con dudosas competencias. (vid. Infra nota 47).

${ }^{20}$ Ley 13/2005, de 1 de julio, por la que se modifica el Código Civil en materia de Derecho a Contraer Matrimonio (BOE núm. 157, de 02-07-2005).

${ }^{21}$ Se facilita el acceso al matrimonio a los menores de edad, incluso dispensando a partir de los 14 años, convirtiéndose en una vía de emancipación (artículo 48, 75, $3142^{\circ}$ y 316 CC.). Igualmente, es posible el acceso al matrimonio de personas incapacitadas judicialmente previo dictamen médico sobre su aptitud para prestar el consentimiento (artículo 56 II CC ). 
Separación y Divorcio. Se facilita el acceso directo al divorcio sin necesidad de pasar previamente por la separación y se acortan los plazos. Se erradica la necesidad de alegar una causa legal para poder separarse o divorciarse. Basta que uno de los cónyuges lo decida para que el primer pronunciamiento de la sentencia sea la disolución del matrimonio, con independencia de las medidas que lleve aparejado ese divorcio. Nadie es obligado a permanecer en el matrimonio en contra de su voluntad. Por último, se introduce el concepto de la guarda y custodia compartida para permitir que los hijos menores del matrimonio puedan conservar las relaciones con ambos progenitores de la manera más amplia posible. Aunque los padres se divorcian, no dejan de ser padres. En el marco de esta ley es donde se encuentra, por primera vez, introducida la mediación en nuestra legislación estatal. Ciertamente, las referencias a la mediación familiar en esta ley son tímidas pero también sirve para anunciar la próxima creación de una ley específica sobre mediación de ámbito estatal (disposición final tercera) ${ }^{22}$.

Efectivamente, la Ley 15/2005, en un intento de disminuir la litigiosidad en los supuestos de separación o divorcio, y siempre en beneficio de los hijos menores de la pareja, ha venido a establecer en el artículo 770.7 de la Ley de Enjuiciamiento Civil, la posibilidad de que las partes puedan, de común acuerdo, solicitar la suspensión del proceso conforme al artículo 19.4 de esta misma ley, para someterse a mediación. La Exposición de Motivos de la Ley 15/2005, de 8 de julio dice que "Con el fin de reducir las consecuencias derivadas de una separación y divorcio para todos los miembros de la familia, mantener la comunicación y el diálogo, y en especial garantizar la protección del interés superior del menor, se establece la mediación como un recurso voluntario alternativo de solución de los litigios familiares por vía de mutuo acuerdo con la intervención de un mediador, imparcial y neutral.”, y establece su Disposición Final Tercera, la obligación del Gobierno de realizar un proyecto de ley sobre mediación, al establecer que "El Gobierno remitirá a las Cortes un proyecto de ley sobre mediación basada en los principios establecidos en las disposiciones de la Unión Europea, y en todo caso en los de voluntariedad, imparcialidad, neutralidad y confidencialidad y en el respeto a los servicios de mediación creados por las Comunidades Autónomas.”

${ }^{22}$ En efecto, la Ley 15/2005 modifica el articulado de la Ley procesal para favorecer un mayor protagonismo a la mediación familiar: el $770.7^{\circ}$ LEC para permitir a las partes de común acuerdo solicitar la suspensión del proceso para solicitar someterse a mediación y en el artículo 771.1 LEC ofrece una ocasión idónea para intentar la mediación en la comparecencia en la que "se intentará un acuerdo de las partes (sic.)". Finalmente el artículo $777.2^{\circ}$ LEC permite aportar, en los procesos promovidos de mutuo acuerdo o instados por una de las partes con el consentimiento de la otra, en el escrito por el que se promueve el procedimiento de separación o divorcio, el acuerdo final alcanzado en el procedimiento de mediación familiar. 
En el comienzo de la X Legislatura, se ha transpuesto finalmente la Directiva, mediante la aprobación de la Ley 5/2012, de 6 de julio, de Mediación en Asuntos Civiles y Mercantiles. De otro lado, ante la inactividad del legislador estatal, hasta la reciente aprobación de dicha Ley, en los distintos territorios autonómicos se han llevado a cabo numerosas diversas iniciativas legislativas en el ámbito de la mediación, sobre todo familiar. Frente a las ventajas del respaldo institucional y seguridad jurídica que para la práctica profesional otorga un marco normativo, se encuentran las desventajas de una normativa territorial muy heterogénea y territorio donde aún no existe regulación.

Existen en España diecisiete Comunidades Autónomas, de las cuales trece cuentan con su propia ley autonómica sobre mediación; por orden cronológico, tales CCAA son: Cataluña, Galicia, Valencia, Canarias, Castilla la Mancha, Castilla y León, Islas Baleares, Madrid, Asturias, País Vasco, Andalucía, Aragón y Cantabria. De hecho, dos de estas CCAA han dictado ya su segunda ley sobre mediación, Cataluña e Islas Baleares ${ }^{23}$.

\section{Coyuntura de la práctica de la mediación en España}

El Derecho y la Administración de Justicia no ofrecen siempre la solución más adecuada y adaptada a todos los casos. Hay que ser conscientes de que en el litigio se van a estimar y desestimar pretensiones de una y otra parte por lo que las medi-

\footnotetext{
${ }^{23}$ Por orden cronológico, las leyes autonómicas que específicamente han regulado la mediación son :

La Ley 1/2001, de 15 de marzo, de mediación familiar de Cataluña, posteriormente derogada por la Ley catalana 15/2009, la Ley 4/2001, de 31 de mayo, de la CA de Galicia, sobre mediación familiar, la Ley 7/2001, de 26 de noviembre, reguladora de la Mediación Familiar en el ámbito de la CA valenciana, la Ley 15/2003, de 8 de abril, de la CA de Canarias, de mediación familiar, la Ley 4/2005, de 24 de mayo, de la CA de Castilla la Mancha, del Servicio Social Especializado de Mediación Familiar, la Ley 1/2006, de 6 de abril, de Mediación Familiar de Castilla y León, la Ley 18/2006, de 22 de noviembre, de la CA de Islas Baleares, de mediación familiar, esta ley ha sido derogada por la Ley 14/2010 de las Islas Baleares, la Ley 1/2007, de 21 de febrero, de Mediación Familiar de la Comunidad de Madrid, la Ley 3/2007, de 23 de marzo, del Principado de Asturias, de Mediación Familiar, la Ley 1/2008, de 8 de febrero, de la CA del País Vasco, de Mediación Familiar, la Ley 1/2009, de 27 de febrero, reguladora de la Mediación Familiar en la Comunidad Autónoma de Andalucía, la Ley de la Generalidad de Cataluña 15/2009, de 22 de julio, de mediación en el ámbito del derecho privado, la Ley 14/2010, de 9 de diciembre, de Mediación Familiar de las Islas Baleares, la Ley 9/2011, de 24 de marzo, de Mediación Familiar de Aragón, la Ley 1/2011, de 28 de marzo, de Mediación de la Comunidad Autónoma de Cantabria.
} 
das resultantes de la sentencia pueden provocar; en mayor o menor medida, la insatisfacción de alguna de ellas. Es evidente que en el proceso judicial se atiende más al pasado y a las pruebas sobre los hechos que han conducido al pleito, mientras que en la mediación se atiende al futuro de las relaciones de las partes para facilitarlas. En efecto, la mediación se muestra especialmente idónea en aquellos casos en los que las partes necesariamente tienen que relacionarse en el futuro (V. gr. relaciones familiares o vecinales) o en las que las relaciones futuras son convenientes para ambos (relaciones comerciales provechosas). Otro de los problemas se centra en la estandarización de las soluciones judiciales, la congestión o saturación de pleitos, y en el hecho de que los conflictos frecuentemente surgen en un contexto emocional difícil que los agrava, tal es el caso de los que implican a personas que tienen relaciones interdependientes que continúan en el tiempo (piénsese en el impacto que la separación o el divorcio tienen sobre todos los miembros de la familia, y especialmente en los niños). Para todos estos supuestos, la mediación es especialmente idónea, sin entrar en el ahorro de tiempo, costes emocionales y económicos que implica este tipo de sistema extrajudicial de resolución de conflictos.

En España se aprecia especialmente la utilidad de la mediación, y particularmente de la mediación familiar, puesto que las estadísticas demuestran la enorme litigiosidad que se ha generado en los últimos años en materia de familia y en concreto sobre crisis matrimoniales o de pareja ${ }^{24}$. Dicha litigiosidad, - que se agrava con la reincidencia, habida cuenta del incremento de los pleitos posteriores a la sentencia de separación o divorcio solicitando modificación de las medidas adoptadas en las mismas (normalmente cambio en la pensión compensatoria, régimen de custodia o visita de hijos y régimen de uso de la vivienda familiar) - hizo necesaria la creación de los Juzgado de Familia como jurisdicción especializada ${ }^{25}$. En este sentido, los

${ }^{24}$ En este sentido se aprecia que si la intención del legislador con la tímida introducción de la mediación en la Ley 15/2005, ya aludida, era disminuir la litigiosidad y promover las separaciones o divorcios de común acuerdo en beneficio de sus hijos menores, lógicamente y como se puede observar, se ha quedado demasiado escueta. En esta Ley únicamente se cita la mediación como un recurso más, sin recomendarlo expresamente y sin darle la importancia que realmente tiene, pues la mediación, además de facilitar que las partes puedan llegar a acuerdos, también persigue que estos sean respetados y duraderos en el tiempo, así como que se mantenga la comunicación entre las partes (que están predestinadas a relacionarse en el futuro) en beneficio de los hijos.

${ }^{25}$ Real Decreto 1322/1981, de 3 de julio, por el que se crean los Juzgados de Familia como especialización de los Juzgados de Primera Instancia. Este Real Decreto se deriva de la Disposición Final de la Ley 11/1981 de 13 de mayo, que modifica el Código Civil en materia de filiación patria potestad y régimen económico del matrimonio. En este precepto legal se previene que el Gobierno "creará y pondrá en funcionamiento el número de Juzgados de Primera Instancia necesarios, en las capitales en que se hallase separada la jurisdicción civil de la penal, que por su población y número de actuaciones relativas al Derecho de 
operadores jurídicos implicados valoran muy positivamente la experiencia de estos juzgados específicos y abogan también por la especialización de los propios jueces, fiscales, secretarios judiciales y abogados de familia. Asimismo, con polémicas excepciones, se considera muy favorable la asistencia del gabinete psicosocial (formado por psicólogos y trabajadores sociales) para informar sobre el estado de los menores e idoneidad de las medidas parentales solicitadas (ANDRÉS JOVEN, $2005)^{26}$.

Teniendo en cuenta esta realidad se han de incardinar las funciones de la mediación familiar y se ha de tratar que pueda paliar, en la medida posible, mucha de la problemática que se manifiesta en este tipo de conflictos (antes, durante y después

Familia lo requieran, los cuales conocerán de forma exclusiva, por vía de reparto, de las actuaciones judiciales previstas en el título VII del libro I de Código Civil". Hay que ser conscientes que la introducción del divorcio en España en el año 1981 produjo un incremento necesario de la litigiosidad y la más reciente reforma en la que se facilita el acceso al divorcio, sin necesidad de separación previa, sin alegar causa legal y acortando los plazos, mediante la Ley 15/2005, de , de 8 de julio, por la que se modifican el Código Civil y la Ley de Enjuiciamiento Civil en materia de separación y divorcio, también ha producido un notable incremento de la litigiosidad en esta materia.

${ }^{26}$ Se han criticado algunos informes de estos equipos psicosociales por considerarlos parciales, poco técnicos, subjetivos o tendenciosos. Incluso se ha advertido de cierta "alegalidad" en la intervención de estos equipos que asisten a jueces y tribunales por no contemplarse en las leyes procesales. Sin embargo, -como bien recoge ANDRÉS JÓVEN- "el art. 92.5 del CC contempla la posibilidad de que el juez de oficio o a petición de los interesados pueda recabar el dictamen de especialistas con el fin de poder adoptar en el ámbito de sus competencias las medidas que estime más beneficiosas para los menores, si bien tal precepto no especifica en modo alguno qué clase de especialistas son aquéllos de los que el Tribunal puede recabar su dictamen, ha de pensarse que éste puede interesar por ejemplo la actuación de profesionales de la medicina -psiquiatras o pediatras- de la sicología, de la asistencia social o de educadores de menores.

Con independencia de esa referencia general que, como ya hemos señalado, permite la intervención de un amplio marco de profesionales, cuando por vía reglamentaria se crearon por parte del Ministerio de Justicia y a instancia del Consejo General del Poder Judicial los diecinueve equipos "de especialistas" para los Juzgados de Familia existentes en aquel momento, en concreto en el mes de noviembre de 1983(3), éstos quedaron constituidos tan sólo por un psicólogo y un asistente social, lo que desde luego a mi juicio no excluye en modo alguno que el Juez pueda valerse de otros profesionales distintos si lo precisa. En la actualidad estos equipos psicosociales dependen, bien del Ministerio de Justicia en aquéllas Comunidades Autónomas en las que todavía no se ha producido la transferencia de competencias en materia de justicia, bien de la correspondiente Comunidad Autónoma en aquellos territorios en los que sí se ha producido esa transferencia." ANDRÉS JÓVEN, J., "El dictamen de especialistas y el dictamen de peritos", en ABEL LLUCH X. Y PICO JUNOY J. (2005) Aspectos prácticos de la prueba civil, Barcelona. 
de los pleitos). También resulta imprescindible establecer los límites a la mediación (v.gr. ante situaciones de violencia de género, aunque parte de la doctrina y la práctica jurisprudencial cuestionan la imposibilidad de aplicar la mediación, de modo genérico a este supuesto (MERINO ORTIZ, 2012) ${ }^{27}$, no procede cuando una o ambas partes se nieguen o desistan respecto al mediador o al proceso de mediación, tampoco se puede utilizar la mediación cuando existan trastornos de comportamiento, mentales o psicológicos graves que afecten de modo importante al entendimiento -deberán derivarse para tratarlos-, casos en los que un punto neutro de acuerdo suponga una injusticia grave por no estar las partes en situación de igualdad, cuando se detecten supuestos delictivos, etc.). Igualmente, y de manera muy especial, es preciso tener presentes los límites en la mediación penal (TORRES FERNÁNDEZ, 2012) ${ }^{28}$.

Para muchos de estos casos se ha de plantear que junto con la asistencia de un gabinete psicosocial exista también el posible auxilio de un mediador familiar ${ }^{29}$. Muchas veces la solución a los conflictos familiares puede alcanzarse por vía extrajudicial con plena satisfacción y con el consiguiente ahorro de costes económicos y emocionales de las familias. En cualquier caso, la racionalización del conflicto a través de la mediación siempre supone que ambas partes van a salir ganando frente al esquema clásico del enfrentamiento contencioso en el que existe una victoria y una derrota judicial o en la que se ven desestimadas pretensiones de ambas partes con la consiguiente insatisfacción. En España se vienen desarrollando, desde hace tiempo, experiencias piloto de mediación intrajudicial en diversos juzgados (fundamentalmente juzgados de familia pero también en juzgados de jurisdicción civil en primera instancia, destacándose la experiencia en Madrid y Valladolid, y en juzgados de lo mercantil, destacándose la reciente experiencia de Bilbao).

Buena parte del éxito de la mediación radica en el elevado nivel de satisfacción y acatamiento voluntario de los acuerdos que se alcanzan tras el proceso (MOORE, 1995:397 ${ }^{30}$. Los acuerdos así adoptados tienen la garantía de ser más ajustados a la realidad y viables, ya que son el resultado del proceso de toma de decisiones de las partes, fruto de su comunicación y de sus propias necesidades; por esta razón, estos

\footnotetext{
${ }^{27}$ MERINO ORTIZ, C. (2012), La mediación familiar en situaciones asimétricas, Madrid

${ }^{28}$ Para un análisis de las diferentes opiniones, vid.., TORRES FERNÁNDEZ E., ¿̇Mediación familiar cuando hay maltrato de pareja?: límites legales y posibilidades reales en los ordenamientos italiano y español.

${ }^{29}$ En este sentido se pronuncia el Protocolo para la implantación de la mediación familiar intrajudicial en los juzgados y tribunales que conocen de procesos de familia, elaborado por el Consejo General del Poder Judicial español en mayo de 2008. Puede consultarse el documento en la página web del Consejo General del Poder Judicial http://www.poderjudicial.es/stfls/PODERJUDICIAL/DOCTRINA/FICHERO/PROTOCOL O\%20CIVIL_1.0.0.pdf

${ }^{30}$ MOORE, C. (1995) El proceso de mediación, 2a Edición, Barcelona,: 397.
} 
acuerdos resultan duraderos y efectivos, ya que no son impuestos por una figura externa, sino que emanan de ellos mismos. Las soluciones adoptadas a través de la mediación están diseñadas a la medida de las partes, asumiéndose por convicción. A través de la mediación se establecen vías de comunicación y negociación entre las partes mediante la definición de expectativas razonables para ambas (FOLBERG y TAYLOR, 1997:157) ${ }^{31}$. Las pautas principales seguidas en la mediación permiten microenfocar los movimientos de las partes, alentar la reflexión de opción de decisiones y promover la aplicación de nuevas perspectivas orientadas hacia el futuro (BUSS y FOLGER, 1996:279-303) ${ }^{32}$.

En cambio, las soluciones adoptadas a través de la sentencia judicial relativa a la separación o el divorcio están estandarizadas y resultan impuestas por la autoridad judicial $^{33}$. Puede llamar la atención las similitudes que guardan entre sí la mayoría de las resoluciones judiciales en materia de separación y divorcio, a pesar del amplio margen de discrecionalidad que la ley otorga ${ }^{34}$. En cualquier caso, es evidente

${ }^{31}$ FOLBERG, J. y TAYLOR, A. (1997) Mediación, resolución de conflictos sin litigio, Mexico,: 157.

${ }^{32}$ BUSS, R.A y FOLGER, J.P. (1996) La promesa de la mediación. Cómo afrontar el conflicto a través del fortalecimiento propio y el reconocimiento de los otros. Barcelona,: 279-303.

${ }^{33}$ La previsión más común en las sentencias de separación y divorcio relativa al régimen de visitas, estancia y comunicación del cónyuge no custodio suele ser similar a la siguiente: " El progenitor del que los hijos ha de vivir separados dispondrá del régimen de comunicaciones, visitas y estancias con ellos, que a continuación se detalla. A) Durante los períodos escolares. Tendrá a sus hijos consigo, los fines de semana alternos, entendiéndose como fin de semana desde el viernes a la salida del colegio hasta el domingo a las 21:00 horas, que deberán ser reintegradas al domicilio del progenitor que ostenta la guarda y custodia. Además, una tarde a la semana, de la salida del colegio a las 20:30 horas, que deberán ser reintegrados al domicilio del cónyuge custodio. B) Durante las vacaciones escolares de Navidad, Semana Santa y Verano u otras que estén o puedan establecerse en el calendario, el cónyuge al que no corresponde la custodia, tendrá a sus hijos consigo la mitad de dichos períodos, correspondiéndole, a falta de otro acuerdo distinto entre los comparecientes, elegir a la madre los años pares, y al padre los años impares.

${ }^{34}$ Este sentido, la ley 15/2005, de ocho de julio, por la que se modifica el código civil y la de enjuiciamiento civil en materia de secta zen y divorcio, ha transformado la regulación respecto a la guarda y custodia de los hijos menores, dando nueva relación al artículo 92 del código civil. La innovación consiste en poder establecer una custodia compartida cuando sea pedida de común acuerdo por los progenitores, o hayan llegado a ese acuerdo a lo largo del procedimiento, o incluso cuando uno sólo lo pida y además tenga el informe favorable del ministerio fiscal (requisito legal dudosamente determinante de la decisión del juez), siempre y cuando esta manera se proteja adecuadamente el interés superior del menor. Con independencia de cómo se establezca la guardia y custodia de los menores, el artículo 94 del código civil se expresa lacónicamente con respecto a los derechos de visita, estancia y comunicación estableciendo: "el progenitor que no tenga consigo a los hijos menores o incapacitados 
que en los procesos contenciosos resulta inevitable que el juez estime las pretensiones de una de las partes desestimando las de la otra parte. En este sentido, siempre habrá una parte victoriosa o vencedora del pleito y otra vencida o perdedora. Incluso, cuando se estiman parcialmente pretensiones de ambas partes, puede que la insatisfacción del resultado obtenido por la sentencia resulte finalmente compartido por las mismas ${ }^{35}$.

En algunas ocasiones, la ley no ofrece parámetros concretos para adoptar decisiones sobre el conflicto sino que deja amplios márgenes de discrecionalidad. Así, resulta especialmente paradigmático el ámbito del derecho de familia en el que la ley está llena, además, de conceptos jurídicos indeterminados (en relación a la discrecionalidad en este contexto, podrían citarse los criterios para establecer una pensión compensatoria del artículo 97 del código civil español o el artículo 163, en los casos en los que se tiene que decidir ante la discrepancia de los padres en el ejercicio de la patria potestad.). Supone una gran dificultad para jueces y tribunales tomar decisiones sobre la vida de una familia cuando no siempre se posee el conocimiento y la información suficientes (VAN MUNSTER, 1996:292) ${ }^{36}$. Tampoco se puede olvidar que las decisiones judiciales se toman debiéndose sujetar a las reglas de la carga y de la práctica de la prueba y al principio dispositivo de rogación de parte.

Es opinión compartida que el procedimiento contencioso se centra en el pasado y alienta la rivalidad u hostilidad, mientras que la utilización de la vía de acuerdos supone mirar hacia el futuro, alentando la cooperación entre las partes ${ }^{37}$. En la mediación las partes se sienten cercanas y diferentes "reconociéndose el uno al otro porque son reconocidos por un tercero o terceros" lo que facilita la comunicación y el acuerdo (SIX, 1995:15) ${ }^{38}$. En la mediación no se delega en un tercero la facultad de decidir sobre lo que es mejor para cada uno, sino que es la propia interacción entre las partes la que hace surgir la mejor alternativa para todos los implicados. Se

gozará del derecho de visitarlos, comunicar con ellos y tenerlos en su compañía”. Si las partes no se ponen de acuerdo, "el juez determinará el tiempo, modo y lugar del ejercicio de este derecho, se podrá limitar o suspender si se tienen graves circunstancias que así lo aconsejen o se incumplieren grave o reiteradamente los deberes impuestos por la resolución judicial".

${ }^{35}$ Se puede afirmar que en la sentencia de separación y divorcio podemos encontrar fórmulas tipo que se repiten miméticamente, por inercia de los tribunales, estableciendo clichés respecto al régimen de visitas, comunicación, estancia del cónyuge no custodio con respecto a los hijos menores de edad.

${ }^{36}$ Esta es la idea que también trasmite VAN MUNSTER, E. (1996). Dilemas en la Mediación Familiar: Aplicaciones Prácticas, Barcelona,: 292.

${ }^{37}$ Por esta razón la mediación está especialmente indicada para aquellos casos en los que las relaciones entre las partes en conflicto deberán continuar necesariamente después de su resolución (crisis matrimoniales con hijos menores de edad, relaciones de vecindad,....)

${ }^{38}$ SIX, J.F., (1997) Dinámica de la mediación. $1^{\text {a }}$ Edición. Barcelona.: 15. 
alcanzan así acuerdos en los que ambas partes salen ganando al alcanzar una resolución productiva del conflicto (SCHIFFRIN, 1996:39 y LUNGREN y WOR-CHEL, 1996:42 $)^{39}$.

\section{La mediación en la jurisprudencia. Receptividad judicial de los principios su aplicación.}

Una buena muestra de la progresiva recepción y éxito en el ejercicio de la mediación en España es la notable disposición de los tribunales de justicia españoles a la introducción de la mediación en el sistema como forma complementaria de acceso a la justicia. Son muchas las sentencias que hacen referencia a la conveniencia y buenos los resultados de la mediación en los pleitos sobre separaciones y divorcios en los que concurren hijos menores de edad. Especialmente, la mediación ha sido especialmente bienvenida desde que en el artículo 92 CC español se ha introducido la guarda y custodia compartida. Incluso, en algunas sentencias, excediéndose obiter dicta sobre el particular han propugnado la conveniencia de la obligatoriedad de la mediación en estos casos ${ }^{40}$. Lo que parece obvio es que un régimen de guarda y custodia compartida solo parece viable si ambos progenitores están dispuestos a colaborar en beneficio del menor para que éste pueda relacionarse de la forma más plena con ambos. Estas necesidades de la realidad práctica y el interés de las Autonomías por fomentar el recurso a la mediación han provocado que la práctica de la mediación supere las carencias del marco legal estatal hasta la aprobación de la Ley 5/2012, el 6 de julio de 2012.

Incluso, yendo más allá de la mediación aplicada al ámbito de los conflictos familiares, merecen destacarse las referencias que en diversas sentencias del Tribunal Supremo (sala $1^{\text {a }}$ de lo civil) se hacen a la conveniencia de intentar la mediación para la solución de las controversias planteadas ante ese tribunal. Cabe destacarse que el ponente de las sentencias citadas es el magistado : Xabier O'Calahan Muñoz.

En la primera de las sentencias, de 2 de julio de 2009, se aborda un curioso caso en el que la acción planteada es una acción declarativa de dominio sobre un inmue-

${ }^{39}$ SCHIFFRIN, A., (1996) Mediación: una transformación en la cultura, Barcelona,: 39, LUNGREN, S. y WORCHEL, S., (1996) "La naturaleza y la resolución del conflicto", en La Mediación y sus Contextos de Aplicación, Barcelona,: 42.

${ }^{40}$ Sirvan como muestra las sentencias del Tribunal Superior de Justicia de Cataluña valorando el otorgamiento de la guardia y custodia compartida en aplicación del art. 79.2 del Código de Familia catalán. En este sentido la sentencia núm. 29/2008, de 31 de julio, (Ref. La Ley. 1636/2008) y la Sentencia de 3 Marzo de 2010, (Ref. La Ley, rec. 152/2008), donde se expresa que la guardia y custodia compartida puede establecerse sin que un alto grado de conflictividad signifique que "(incluso) no deba procurarse su implantación cuando resulta beneficiosa para los menores, aunque sea imponiendo en determinados casos la mediación familiar o terapias educativas." 
ble. El actor alegaba que era el verdadero propietario de una vivienda cuya titularidad aparecía a favor de su antigua suegra (madre de su exmujer) debido a un negocio simulado o fiduciario, que encubría un préstamo que la titular aparente hizo a favor de quien ahora reclama la titularidad para la adquisición del mismo. De contrario, la demandada defendía su propiedad y declaraba que el demandante ocupaba el piso como arrendatario. Ante esta extraña situación planteada, el Tribunal refleja que el caso "se presenta como un simple tema de propiedad, como declaración del dominio o como un ejercicio de opción de compra, pero presenta un trasfondo del conflicto familiar, que se vislumbra, pero no aparece con prueba suficiente para decidir sobre una u otra de las dos acciones contradictorias entre sí. Podría haber algo más que un simple contrato de arrendamiento urbano, que podría llevarse a una mediación, si las partes hubieran querido o una ley lo hubiera previsto, aunque no la hay, si bien todo apunta a una corriente favorable a la misma (...)”.

Posteriormente, se incide, en la idoneidad de la mediación para resolver el problema planteado en la sentencia de 3 de julio de 2009, en la que se sustancia un problema relativo a una revocación de una donación modal realizada conjuntamente por ambos cónyuges a uno de sus hijos. Uno de los cónyuges fallece y el supérstite pretende revocar la donación al considerar que no se cumplió el modo. En este caso, la sentencia observa que "Se trata, pues, de un fuerte enfrentamiento familiar, con la consecuencia jurídica de un largo y enconado proceso y la consecuencia económica, según la sentencia recurrida, de la pérdida de una larga serie de bienes por el demandado donatario que había sido objeto de la mencionada donación. No es baldío tener presente que en éste, como en otros tantos conflictos, tanto familiares, como civiles o mercantiles en general (así, Directiva 2008/52/CE del Parlamento europeo y del Consejo de 21 de mayo de 2008, sobre ciertos aspectos de la mediación en asuntos civiles y mercantiles), podría una mediación llegar a soluciones menos traumáticas que el proceso y el acuerdo a que se podría llegar siempre sería menos duro que la resolución judicial que se apoya exclusivamente en la aplicación de la norma jurídica".

En una tercera sentencia, de 17 de septiembre de 2009, se reitera de idéntica manera la conveniencia de acudir a la mediación para resolver el problema. En este caso, "se trata de un enfrentamiento familiar por razón -más frecuente de lo que debiera- de la herencia paterna y ha provocado un largo y costoso proceso que, como ya observaba la sentencia de esta Sala 3 de julio del presente año, podría una mediación haber evitado (...)”.

En la sentencia de 20 de mayo de 2010 se aborda un conflicto en una sucesión testamentaria. En este caso se reiteran las ideas ya plasmadas en las sentencias anteriores que son citadas por el propio tribunal y se añaden referencias al marco legal de la mediación, incluyendo el malogrado Proyecto estatal "Este caso, propio de una sucesión mortis causa, no sólo refleja un problema de atribuciones patrimoniales, sino un enfrentamiento familiar, que se vislumbra claramente en los escritos obrantes en autos, que podría haberse evitado yendo a la solución alternativa de la mediación, si las partes hubieran querido o la ley lo hubiera previsto, que no la hay, pero aparece cada vez más una corriente favorable a la misma, que ha tenido 
reflejo legal en la Directiva 2008/52 / CE del Parlamento Europeo y del Consejo, de 21 de mayo de 2008, sobre ciertos aspectos de la mediación en asuntos civiles y mercantiles, en la Ley 15/2009, de 22 de julio, de la Comunidad Autónoma de Cataluña, de mediación en el ámbito del Derecho Privado, y en el Anteproyecto de Ley de mediación en asuntos civiles y mercantiles, elevado al Consejo de Ministros por el de Justicia el 19 de febrero de 2010. En todo caso, puede la mediación, como modalidad alternativa de solución de conflictos, llegar a soluciones menos traumáticas que el dilatado tiempo que se invierte en el proceso y el acuerdo a que se llega siempre será menos duro que la resolución judicial que se apoya exclusivamente en la razonada aplicación de la norma jurídica".

Resulta alentador para la mediación que los jueces y tribunales generen confianza en los justiciables que deseen acudir a la misma. Es evidente que si los jueces y tribunales derivan a mediación está asegurada buena parte del éxito de la práctica de la mediación intrajudicial. De hecho, uno de los principales factores del desarrollo de los sistemas de A.D.R. (alternative dispute resolution) en EE.UU. pasa por la derivación judicial y el mucho más amplio margen de discreccionalidad judicial en la dirección y planificación procesal que tienen los jueces estadounidenses (VAZQUE DE CASTRO, 2009: 1045-1063) ${ }^{41}$. Incluso, con sentencias que manifiestan las ventajas de la mediación es posible que los abogados comiencen a convencerse de que la mediación es una buena opción que puede facilitar su trabajo y aconsejen a sus clientes el intentar una mediación previa antes de iniciar un proceso contencioso. De esta manera, también la mediación extrajudicial se verá impulsada por la confianza que inspiran las recomendaciones judiciales que se han observado.

Resulta también cierto que con la observancia de las sentencias y de la práctica de la mediación se puede percibir una evolución o reinterpretación de los principios de la mediación que dan muestras de madurez y consolidación de esta institución. En las fases iniciales de introducción de figuras o conceptos jurídicos se tiende a la rigidez y a la dogmática para reafirmar la identidad y características de las mismas. Sin embargo, con la seguridad del inequívoco reconocimiento y aplicación se ceden posiciones dogmáticas para acomodar las nuevas figuras con flexibilidad a la evolución práctica. En este sentido, se están planteando relecturas de los principios esenciales que inicialmente se consideraban como absolutos e inamovibles.

${ }^{41}$ Hasta tal punto llega la persuasión de los jueces americanos a acudir a mediación que, alguna de las posiciones críticas en EE.UU, llevaron a definir las ADR como la creación de incentivos o presiones que fuerza a los litigantes a pactar. (OWEN. M. F. (1985) "Out of eden” Yale Law Review.) Contestado por LIEBERMAN, JK, HENRY J.F., (1986) "Lessons from the Alternative Dispute Resolution Movement", The University of Chicago Law Review, Vol. 53, No. 2. Spring,:424-439. (vid. con más detalle VÁQUEZ DE CASTRO, E., (2009)“La Mediación como método moderno de gestión de conflictos: Expansión desde EE.UU”, Estudios de Derecho Español y Europeo, Santander,: 1045-1063). 


\section{El resultado de la evolución: La ley española de mediación en asuntos civiles y mercantiles.}

Como puede observarse, la Ley de Mediación española, pretende ir más allá del contenido de la Directiva 2008/52/CE. Tal extralimitación no está mal vista por los órganos de la Unión Europea, si nos atenemos al apartado 9 del Informe sobre la aplicación de la Directiva sobre la mediación en los Estados miembros, su impacto en la mediación y su aceptación por los Tribunales (2011/2026(INI)), aprobado el 11 de julio de 2011. A tenor del mismo : "los Estados miembros cuya legislación nacional va más allá de los requisitos básicos de la Directiva sobre la mediación parecen haber logrado resultados importantes en la promoción del tratamiento no judicial de los conflictos en materia civil y mercantil”.

El largo camino que se ha recorrido hasta la aprobación de la Ley de mediación española 5/2012, que incorpora al Derecho español la Directiva 52/2008, trae su causa y se sirve de la experiencia, de las leyes autonómicas, de la jurisprudencia y de una larga tramitación parlamentaria, contando con el decaído texto normativo que resultó frustrado en la legislatura anterior, y pasando finalmente por la aprobación del Real Decreto ley 5/2012, de 5 de marzo, de Mediación en Asuntos Civiles y Mercantiles, convalidado por el Congreso de los Diputados el 29 de marzo de 2012, tramitado posteriormente como Proyecto de Ley por vía de urgencia, para concluir finalmente en la referida Ley 5/ 2012, de 6 de julio.De hecho, la actual Ley se aleja poco de lo proyectado con anterioridad, aunque algunos cambios son relevantes. Por ejemplo, resulta evidente que la mediación debe ser un procedimiento ágil y rápido para que resulte eficaz. Sin embargo, resulta llamativo que la Ley no establezca una duración máxima ${ }^{42}$, como fijaba el proyecto anterior cifrándolo en dos meses, sino que se limite a prevenir que será lo más breve posible y sus actuaciones se concentrarán en el mínimo número de sesiones (art. 20). En todo caso, si la mediación es intrajudicial al surgir la posibilidad de acuerdo cuando ya se ha iniciado el proceso judicial se ha previsto la suspensión del proceso. La Ley se refiere a los efectos de la mediación sobre los plazos de prescripción y caducidad con la previsión de suspensión de la caducidad o la interrupción de la prescripción (art. 4). No obstante, la suspensión no puede ir más allá de 60 días si la mediación interrumpe un pleito ya comenzado (art. 19.4 LEC). Sin embargo, se pueden apreciar novedades de más amplio calado cuando se analizan los principios reflejados en su articulado.

En este sentido, se reinterpreta el principio de voluntariedad. ¿Debe ser la mediación asumida espontáneamente? ¿ ¿Si existiese alguna derivación obligatoria no funcionaría la mediación? Sobre estas cuestiones parece haberse asumido que la obligatoriedad de una sesión informativa sobre las posibilidades del proceso de

42 Probablemente se omite esta cuestión para evitar contradicciones con lo ya dispuesto como plazo máximo por las Leyes autonómicas. 
mediación no rompe el principio de voluntariedad. Parecía que esa era la línea que iba a seguir el legislador español en el malogrado Proyecto de Ley de la anterior legislatura, sin embargo, la Ley de Mediación resultante no deja duda del absoluto carácter voluntario de la mediación en España (art. 6). De esta manera se sigue la línea de los países europeos de nuestro entorno, de la que se apartó Italia. El legislador italiano, con el fin ya declarado de reducir el número de expedientes judiciales, había apostado fuertemente por la "mediación obligatoria", ampliando de manera considerable la tipología de controversias que tendrán que pasar, bajo pena de inadmisibilidad de la demanda, por un intento de mediación (Art. 5.1 del Decreto Legislativo núm. 28, de 4 de marzo de 2010) y tanto la parte, como el juez ex oficio, podrán alegar la excepción de inadmisibilidad temporánea de la demanda. Sin embargo, este régimen jurídico ha cambiado. Recientemente, el Tribunal Constitucional Italiano en la sentencia de 23 de octubre de 2012 ha tomado la decisión relativa a inconstitucionalidad del Decreto Legislativo n. 28/2010, declarándolo inconstitucional en este punto de la obligatoriedad, aunque sólo por motivos formales, porque no ha respetado a la Ley de delegación n. 69/2009 (art. 60). En efecto, los jueces constitucionales no declararon la mediación civil obligatoria (art. 5,I, D.Lgs. n. 28/2010) inconstitucional porque estuviese en conflicto con el principio contenido en el art. 24 de la Const. (es decir por vulnerar el principio de tutela judicial efectiva), sino porque la solución favorable a la obligatoriedad no estaba prevista en la Ley de Bases que sirvió de delegación para el texto articulado finalmente aprobado.

En España, el frustrado Proyecto de Ley de la pasada legislatura limitaba dicha obligatoriedad a los juicios verbales (6.000 Euros) que consistan en una reclamación de cantidad (art. 7.1 Proyecto de Ley). Éste ha sido uno de los pocos aspectos que, finalmente, fue modificado en la Ley 5/2012, de 5 de marzo, puesto que la mediación se configura con carácter voluntario, de forma que no se contempla ninguna obligación legal de acudir a mediación. No obstante, el juez, cuando aprecie que en atención a la naturaleza del litigio éste podría resolverse de forma más ágil y menos costosa a través de la mediación, podrá instar a las partes a que asistan a una sesión informativa (art. 6).

Aunque el principio de Imparcialidad debe resultar incuestionablemente intocable, se está planteando flexibilizar el principio de Neutralidad. ¿Si existe desequilibrio de poder no puede el mediador ser directivo para equilibrar la posición de las partes (empowerment)? Nadie cuestiona que las habilidades del mediador deben servir para procurar que exista un equilibrio entre las partes y evitar que una de las partes juegue un papel más débil en la negociación o evitar que los acuerdos se adopten con vicios del consentimiento. Estas situaciones requieren una posición más activa del mediador aunque no puede pasar en modo alguno por realizar propuestas de acuerdo a las partes, porque la propia esencia de la mediacion, que afecta al protagonismo de aquéllas, quedaría desdibujada. No obstante, volviendo de nuevo a Italia podría considerarse obviado este principio, al admitirse la posibilidad para el mediador de formular una propuesta de acuerdo, tanto si las partes así lo solicitan, como motu proprio en el caso de que no sea posible alcanzar un pacto 
(Art. 11 del Decreto Legislativo núm. 28, de 4 de marzo de 2010). Lo que es realmente peculiar, y fuente de críticas, es la posibilidad para el juez de condenar en costas a la parte que gana el juicio en el caso de que el contenido del fallo coincida con la propuesta de acuerdo que había sido formulada por el mediador y rechazada por la parte ganadora del pleito (Art. 13.1 del Decreto Legislativo núm. 28, de 4 de marzo de 2010 ${ }^{43}$.

El principio de Confidencialidad es uno de los pilares sobre los que se sientan las bases de la mediación (art. 9). Este principio no lo cuestiona ningún mediador pero el Tribunal Supremo español ha valorado como prueba en juicios las actas intermedias de mediación presentadas por las partes en la Sentencia $N^{\circ}: 109 / 2011$, de 10 de febrero de 2011, de la sala de lo civil. El Tribunal Supremo argumenta que la Ley de Enjuiciamiento Civil española obliga a los jueces a considerar como prueba documental, conforme a la sana crítica, los documentos aportados por las partes que tengan relación con el pleito. La materia procesal es competencia del Estado y no de las CC.AA. por lo que las Leyes autonómicas no afectan en este punto la tarea jurisdiccional. Así, aunque las referidas Leyes contemplen la confidencialidad y el secreto profesional, sólo una modificación de la Ley de Enjuiciamiento Civil que impidiese valorar como prueba esos documentos evitaría su consideración por los tribunales. En todo caso, estos riesgos son perfectamente evitables puesto que no sería necesario que los mediadores facilitasen las actas intermedias a las partes, salvo que efectivamente contemplen acuerdos alcanzados por ellas . Estos acuerdos tendrían fuerza vinculante en sí mismos desde que existan en virtud de la autonomía de la voluntad (arts. 1255 y 1091 del Código Civil español). Con el actual artículo 9 están contemplados los deberes de confidencialidad del mediador y de las partes, aunque estas últimas, de modo cuestionable (GARCÍA VILLALUENGA, 2012. 129-138) ${ }^{44}$.

Algunas leyes autonómicas incluyen la inmediatividad o presencialidad como principio, evitando la mediación realizada con representantes de las partes. No obstante, la mediación electrónica cuestiona la presencialidad o necesidad de presencia simultánea o síncrona de las partes y la asistencia personal de las partes a la mediación se cuestiona en la mediación empresarial o comercial. No obstante, cada vez se observa mayor receptividad hacia la mediación realizada por medios electrónicos. Sistemas de mediación on line contemplados en algunos artículos de la Ley (artículos 5 (apartado 2), 24 y Disposición Final Séptima). Además, la Directiva 2008/52/CE, en su considerando 9 expresamente indica que "La presente Directiva no debe impedir en modo alguno la utilización de las nuevas tecnologías de comunicaciones en los procedimientos de mediación."

${ }^{43}$ Vid. también, más recientemente, el Reglamento de desarrollo del Decreto Legislativo n. 28/2010 (Decreto Ministeriales 6.7.2011 n. 145) en vigor desde el 26 de agosto de 2011.

${ }^{44}$ García Villaluenga, L (2012), “Comentario al art. 9” en Comentarios a la Ley 5/2012 de mediación en asuntos civiles y mercantiles. Madrid:129- 138 
El principio de calidad de la mediación que se traduce en la adopción de códigos deontológicos y la cualificación profesional de quienes van a ejercer la mediación también encuentra reflejo en la exigencia de una formación específica. De esta manera, se cumple la previsión del artículo 4 de la Directiva que exige una formación inicial y continua del mediador. No obstante, se deja a un desarrollo reglamentario posterior la concreción de esta exigencia. Aunque no se exige una titulación universitaria de base, ni una necesidad de registro central (al menos inicialmente), se exige tener un seguro profesional que cubra los riesgos (art. 11). Realmente, es este uno de los puntos clave que sería preciso unificar al haberse atomizado las exigencias para el ejercicio de la mediación en las diversas CC.AA. Esta uniformidad sería deseable que se pudiese alcanzar o asumir en Europa para favorecer el libre ejercicio profesional y la movilidad de trabajadores. La Ley 17/2009, de 23 de noviembre, sobre el libre acceso a las actividades de servicios y su ejercicio, ha incorporado, parcialmente, al Derecho español, la Directiva 2006/123/CE del Parlamento Europeo y del Consejo, de 12 de diciembre de 2006, relativa a los servicios en el mercado interior que trata de remover los obstáculos o trabas innecesarios para el libre ejercicio profesional o la libre prestación de servicios profesionales.

También, merece destacarse que, en su último título (arts. 25-27), la Ley establece de forma novedosa la ejecutividad de los acuerdos alcanzados. La ejecutividad se obtiene elevando el acuerdo alcanzado en mediación a escritura pública con la intervención de un notario. Aunque los acuerdos de mediación tienen un índice de cumplimiento voluntario por las partes muy superior al de los laudos arbitrales y las sentencias, el facilitar su ejecutividad supone incrementar su eficacia. Si el acuerdo se alcanza en una mediación intrajudicial, la homologación y ejecución del mismo podrá solicitarse ante el propio Tribunal que conoce del caso. Esta forma de otorgar fuerza ejecutiva a los acuerdos alcanzados en mediación no pueden extenderse a las mediaciones familiares en las que intervengan hijos menores de edad. Para estos casos deberá usarse la vía de la homologación judicial puesto que se requerirá intervención del Ministerio Fiscal y la revisión del Juez para asegurarse que no se vulnera el interés superior de los menores (arts. 25.4 Ley 5/2012, 90 y 92 $\mathrm{CC})$.

\section{La Oportunidad de la Ley estatal de mediación en asuntos civiles y mer- cantiles.}

Finalmente, a modo expuesto, debe advertirse que la situación de la práctica de la mediación en España va por buen camino en la difusión, evolución y recepción de los operadores jurídicos, pero hay que ser conscientes de que el grado de aplicación e introducción en la sociedad es incipiente (GARCÍA VILLALUENGA, 2006: 315 
y ss. $)^{45}$. Queda aún un largo camino por recorrer para que la mediación resulte ser el modo habitual de resolver los conflictos en España y que acudir a los tribunales de justicia sea el último recurso, cuando la vía de la mediación haya resultado infructuosa o improcedente. Podría considerarse, siguiendo un paralelismo con la psicología evolutiva, que el estado actual de crecimiento de la mediación en España, tomando en cuenta la primera Ley de Mediación Familiar de 2001, habría superado la niñez, quedando aún el difícil camino de la adolescencia que logrará desembocar en la madurez. Esta madurez se alcanzará con el desarrollo de la actual Ley estatal de Mediación en Asuntos Civiles y Mercantiles y las nuevas Leyes de Mediación Autonómicas que podrán considerarse de segunda generación y que ya han visto la luz en Cataluña y en Cantabria ${ }^{46}$.

En efecto, uno de los principales factores que confiamos contribuya a la consolidación y madurez de la institución de la mediación en España es la aprobación de su marco jurídico completo a nivel estatal. Regulación marco que se aprobó mediante la Ley 5/2012, de 6 de julio, de Mediación en Asuntos Civiles y Mercantiles, El respaldo normativo ofrece una gran seguridad jurídica y viene a satisfacer una demanda generalizada de la sociedad ${ }^{47}$.

En este camino evolutivo ya se está alcanzando uno de los máximos exponentes de la vanguardia en la mediación como es el uso de las nuevas tecnologías para desarrollar la mediación electrónica y otros sistemas de O.D.R. (Online Dispute Resolution $)^{48}$. Por el camino se ha dado un paso importante en la consolidación de la mediación al trascender su regulación del ámbito familiar a los ámbitos de la mediación desarrollada por medios electrónicos. Éste es uno de los procedimientos que se ha previsto implantar mediante la Ley de Mediación en Asuntos Civiles y

${ }^{45}$ Respecto a los orígenes de la mediación familiar en España vid. por todos GARCÍA VILLALUENGA, L., (2006) Mediación en Conflictos Familiares, Madrid,: 315 y ss.

${ }^{46}$ Puede servir como referencia que la primera Ley de Mediación en España que se aprueba en Cataluña data de 2001 y ya recoge una incipiente práctica que aún resultaba desconocida en otros territorios. En estos once años de experiencia ya se están empezando a apreciar los beneficiosos efectos de la mediación en la práctica jurídica española.

${ }^{47}$ Decreto - Ley convalidado por el Congreso de los Diputados el 29 de marzo de 2012 y tramitado posteriormente como Proyecto de Ley por vía de urgencia, concluyendo con la Ley 5/2012, de 6 de julio. Atrás queda la iniciativa legislativa que inició su trámite parlamentario como Proyecto de Ley de Mediación en Asuntos Civiles y Mercantiles. , que quedó frustrada ante las sucesivas ampliaciones de plazos para la presentación de enmiendas y la sobrevenida disolución del Congreso de los Diputados al finalizar la legislatura por la convocatoria anticipada de elecciones generales para el 20 de noviembre de 2011.

${ }^{48}$ Éste es el objeto del Proyecto de investigación Proyecto de Investigación del Plan Nacional de I+D+i denominado "Resolución de disputas en línea”, Ref. DER2010-19772 (subprograma JURI). Proyecto cuyo investigador principal es Eduardo Vázquez de Castro coautor de este artículo. 
Mercantiles denominándose "mediación simplificada"49. De hecho, este fenómeno de resolución de disputas en línea supone una revolución en la justicia que se contagia de la revolución tecnológica en la que estamos inmersos en la sociedad del siglo XXI.

También merece destacarse que en su último título (arts. 25-27), la Ley establece de forma novedosa la ejecutividad de los acuerdos alcanzados. La ejecutividad se obtiene elevando el acuerdo alcanzado en mediación a escritura pública con la intervención de un notario. Aunque los acuerdos de mediación tienen un índice de cumplimiento voluntario por las partes muy superior al de los laudos arbitrales y las sentencias, el facilitar su ejecutividad supone elevar su eficacia. Si el acuerdo se alcanza en una mediación intrajudicial, la homologación y ejecución del mismo podrá solicitarse ante el propio Tribunal que conoce del caso. De lege ferenda, se podría proponer que, en lugar del Juez, quien homologase los acuerdos alcanzados en mediación, sea el secretario judicial. Con esta medida se le descargaría al Juez de esta tarea para que agilizase el resto de sus funciones. Además, el secretario judicial tiene carácter de fedatario público por lo que también podrían predicarse de estos acuerdos intervenidos o firmados por el secretario judicial el carácter de ejecutivo. En todo caso, la Ley marca silencio sobre tales extremos. Del mismo modo que los notarios han visto reconocida en la Ley 5/2012 un papel decisivo en la mediación, debe añadirse que en la regulación de la nueva oficina judicial se prevén nuevas formas de resoluciones o decisiones en las que no interviene el Juez sino el resto de profesionales junto con las partes.

De todo lo hasta aquí expuesto, puede observarse una tendencia expansiva de la mediación a todos los ámbitos del conflicto. Es evidente que en España se ha producido una vis atractiva del proceso de mediación que iniciándose en el ámbito familiar ha terminado por aplicarse a todos los campos del Derecho Privado, donde ya cuenta con un marco normativo adecuado. No obstante, el poder expansivo de la mediación no acaba en el Derecho Privado y ya se cuenta con experiencias piloto y protocolos de mediación en otros ámbitos como el laboral, el penal (fundamentalmente con menores infractores) y poco tardará en aplicarse a las relaciones con la Administración, aunque no sean ámbito de aplicación de la Ley nacional referida.

En conclusión, es cierto que la mediación no es la panacea, y que no deben tratarse de solucionar todas las controversias a través de la mediación. De hecho,

${ }^{49}$ La Ley 5/2012, de 6 de julio, de mediación en asuntos civiles y mercantiles contempla importantes referencias sobre la mediación electrónica, tales como:

- $\quad$ La mediación electrónica podrá ofrecerse por las instituciones de mediación (art. 5.).

- La mediación que consista en una reclamación de cantidad que no exceda de 600 euros se desarrollará preferentemente por medios electrónicos, salvo que el empleo de éstos no sea posible para alguna de las partes (art. 24).

- El Gobierno promoverá la resolución de los conflictos que versen sobre meras reclamaciones de cantidad a través de un procedimiento de mediación simplificado que se desarrollará exclusivamente por medios electrónicos. (D.F. $7^{\circ}$ ). 
existen otros sistemas de solución extrajudicial que, en ocasiones, podrían resultar más idóneos que la mediación, dependiendo de la tipología de conflictos. Incluso, habrá casos en los que la mediación no resulte indicada. También es cierto que la norma aprobada en España es susceptible de mejoras, en su desarrollo reglamentario y en la praxis.

El tiempo dirá si la comunidad jurídica, empresarial y la sociedad española están decididas a convertirla en una vía relevante y eficaz en la solución de conflictos. Buena parte del éxito de la mediación dependerá de la confianza de la ciudadanía en la cualificación y profesionalidad de quienes ejercen la mediación. La posible cobertura de responsabilidad con la suscripción de un seguro profesional que exige la Ley (art. 11.3) es una garantía necesaria pero lo importante es prevenir esa posible responsabilidad o negligencia desde la mejor cualificación profesional. Por este motivo, en estos momentos de incipiente desarrollo de la mediación debe hacerse especial esfuerzo por exigir una formación inicial y continua de calidad a quienes se encargarán de prestigiar esta faceta profesional uniformando los dispares criterios autonómicos. En este sentido, la Ley exige en el estatuto del mediador, como requisito para poder ejercer su labor, una formación específica en mediación en dos de sus preceptos (arts. 11.2 y 12). No obstante, se habrá de esperar al desarrollo reglamentario de la Ley para poder conocer con detalle las características de los previstos cursos específicos y de las instituciones debidamente acreditadas que los impartan. También, la propia exigencia de las Instituciones de mediación a la hora de admitir en sus registros sólo a los mediadores más cualificados servirá como filtro y prestigio de la profesión.

\section{Referencias bibliográficas}

Andrés Jóven, J., "El dictamen de especialistas y el dictamen de peritos", en ABEL LLUCH X. Y PICO JUNOY J. (2005) Aspectos prácticos de la prueba civil, Barcelona.

BUSS, R.A y FOLGER, J.P. (1996) La promesa de la mediación. Cómo afrontar el conflicto a través del fortalecimiento propio y el reconocimiento de los otros. Barcelona.

Castán Tobeñas (1994), Derecho Civil Común y Foral, T.V, Vol 1º, Madrid.

DÍEZ-PICAZO y GULLÓN (2006) "Evolución profunda originada por los cambios producidos en los hábitos y en las creencias sociales” según Sistema de Derecho Civil , Vol. IV, Madrid.

Folberg, J. y Taylor, A. (1997) Mediación, resolución de conflictos sin litigio, México.

García Villaluenga, L. (2006): Mediación en conflictos familiares. Una construcción desde el derecho de familia. Ed. Reus, Madrid.

Garcia Villaluenga, L (2012), “Comentario al art. 9” en Comentarios a la Ley 5/2012 de mediación en asuntos civiles y mercantiles. Madrid. 
Lacruz Berdejo y otros (2005), en Elementos de Derecho Civil , T. IV, Familia, ${ }^{\mathrm{a}}$ ed., Madrid.

Lieberman, Jk, Henry J.F.,(1986) "Lessons from the Alternative Dispute Resolution Movement", The University of Chicago Law Review, Vol. 53, No. 2. Spring.

Lungren, S. Y Worchel, S., (1996) "La naturaleza y la resolución del conflicto", en La Mediación y sus Contextos de Aplicación, Barcelona.

Merino Ortiz, C. (2012), La mediación familiar en situaciones asimétricas, Madrid

Moore, C. (1995) El proceso de mediación, $2^{a}$ Edición, Barcelona.

Owen. M. F. (1985) "Out of eden” Yale Law Review

Schiffrin, A., (1996) Mediación: una transformación en la cultura, Barcelona.

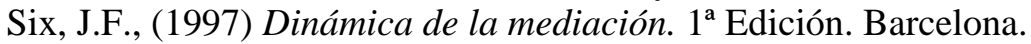

Soleto Muñoz, H. (2011): Mediación y resolución de conflictos: técnicas y ámbitos. Ed. Tecnos, Madrid.

Torres Fernández E. (2012), ¿ Mediación familiar cuando hay maltrato de pareja?: límites legales y posibilidades reales en los ordenamientos italiano y español, en "Le ragioni degli altri" mediazione e famiglia tra conflitto e dialogo Una prospettiva comparatistica ed interdisciplinare. Firenze

Van Munster, E. (1996). Dilemas en la Mediación Familiar: Aplicaciones Prácticas, Barcelona.

Váquez De Castro, E., (2009)“La Mediación como método moderno de gestión de conflictos: Expansión desde EE.UU”, Estudios de Derecho Español y Europeo, Santander.

Vázquez De Castro, E., García Villaluenga, L. (2010) "La mediación y la formación del mediador. ¿dos caras de una misma moneda?”, Mediación, arbitraje y resolución extrajudicial de conflictos en el siglo XXI. La Mediación. ed. Reus, Tomo I. Madrid.

Vázquez De Castro, E., (2012), “Comentario al art. 24” en Comentarios a la Ley 5/2012 de mediación en asuntos civiles y mercantiles. Madrid. 